\title{
Improvement of torque undulation in BLDC using SEPIC and common end diode clamped three-level inverter
}

\author{
Manoj Kumar $\mathbf{N}^{1 *}$, Kavaskar $\mathbf{S}^{2}$ and Hariramakrishnan $\mathbf{P}^{3}$ \\ Department of Electrical Engineering, Panimalar Engineering College, Chennai 600123 Tamil Nadu, India ${ }^{1}$ \\ Senior Engineer -Power System Studies, Power Projects Private Ltd, Chennai 600116, Tamil Nadu, India ${ }^{2}$ \\ Department of Electrical Engineering, Panimalar Engineering College, Chennai 600123 Tamil Nadu, India ${ }^{3}$
}

Received: 12-August-2021; Revised: 16-December-2021; Accepted: 21-December-2021

(C)2021 Manoj Kumar N et al. This is an open access article distributed under the Creative Commons Attribution (CC BY) License, which permits unrestricted use, distribution, and reproduction in any medium, provided the original work is properly cited.

\begin{abstract}
Brushless Direct Current Motor (BLDC) is extensively used in medium and high-power applications for robust construction and flexibility in operation. The commutation of BLDC motor in the high-speed region provides torque undulation in three-level inverter systems. This paper presents an improved converter method for minimizing the torque undulation in BLDC motor for three-level systems using the trapezoidal back Electromotive Force (emf) method. To regulate constant voltage improved Single-Ended Primary Inductor Converter (SEPIC) is used and further to reduce torque undulation, the 3-Level Common End Diode Clamped inverter (3-LCEDCI) is designed into the scheduled circuit. Experimental validation of BLDC motor for a switching frequency of $5 \mathrm{KHz}$ using 3-LCEDCI maintains constant speed for variation in load. Fuzzy based BLDC motor is used further to improve the torque undulation for various switching frequencies. The execution of the scheduled approach is simulated using MATLAB/Simulink under closed-loop operation and compared with the experimental setup to validate the speed for various switching frequencies.
\end{abstract}

\section{Keywords}

BLDC, SEPIC, 3-LCEDCI, BLDC motor.

\section{Introduction}

Brushless Direct Current (BLDC) motor is a 3-phase brushless permanent sine wave motor fed from an adjustable oscillated inverter managed through a halleffect sensor. A BLDC motor is a DC motor with an armature on the stator side and a field winding on the rotor side. BLDC is an improved 3-phase brushless permanent magnet sine wave motor where Sinusoidal Counter-Electromotive Force (SCE) is replaced by Trapezoidal Counter-Electromotive Force (TCE) in BLDC motor. The turn-off region in the counterElectromotive Force (emf) of a BLDC motor must be smaller to commutate the phase current of the motor [1]. In $120^{\circ}$ mode, trapezoidal back-emf will be constant for producing smooth torque. To turn off armature current, electronic commutation is replaced in BLDC motor, which abolishes the problems associated with firing and enervating, thereby making a BLDC a robust machine [1].

\footnotetext{
*Author for correspondence
}

BLDC drive has been replaced from Induction Motor (IM) drive in servo applications [2-4] with improved power factor. To improve the speed and to provide smooth torque during transient conditions, torque and flux are controlled using conventional two-level inverter systems. The phase current of the inverter gets distorted, which produces torque distortion in a conventional method. Several converter topologies with DC-DC converters are suggested to improve the torque distortion. Conventional three-level inverters create large back emf and fast switching action during high-speed operation. The three-level inverter produces a large current ripple which leads to torque ripple and vibration. The problem associated can be reduced by replacing conventional three-level inverter with Single-Ended Primary Inductor (SEPI) converter fed BLDC motor [5, 6]. The main goal of our suggested method is to minimize the torque distortion and improve the performance of the BLDC motor.

The work is intended:

- To develop an improved single Single-Ended 
Primary Inductor Converter (SEPIC)-based 3Level Common End Diode Clamped inverter (3LCEDC) inverter for BLDC motor in closedloop mode to reduce the current and torque undulation.

- To evaluate the performance and response under different operating conditions

- The fuzzy interference system is constructed and the performance is compared with 3-LCEDC inverter for BLDC motor.

The proposed 3-LCEDC inverter for BLDC motor reduces the torque undulation and to maintain constant voltage improved SEPI converter is used. The experimental setup is used to validate the above simulation results. To smoothen the speed response and torque ripple fuzzy systems are added to BLDC motors.

The proposed work is oriented in different sections. The literature review is briefed in section 2. Section 3 discusses the modeling of the BLDC drive system for three levels of the inverter. Section 4 and 5 shows the experimental validation and discussion. Conclusion and future scope are discussed in section 6 .

\section{Literature review}

Anvari et al. [7] added a ZETA converter in the BLDC motor drive to reduce torque undulation, Proportional Integral (PI) controllers to control the speed of the motor, and sensors to find the rotor position. The benefit of adding a ZETA converter to reduce torque undulation and parameter setting of PI controllers manually for different speed is very difficult and the cost of hall sensors increases the cost of the drive.

Arunkumar and Thangavel [8] discussed different multilevel inverters mainly focusing on cascaded multilevel inverters, which reduce the switching stress, better efficiency, and fewer ripples in stator current. Although cascaded inverter uses fewer components, but requires an isolated DC source for power conversion when compared to other multilevel inverters.

Ozturk and Toliyat [9] provided an indirect stator flux control where the d-axis is taken as the reference to operate in the flux weakening region and process the speed error in the hysteresis comparator to achieve a fast torque response. This method provides advantages of the classical Direct Torque Control (DTC) such as fast torque response compared to vector control and a position-sensor less drive. The rotor flux is not sinusoidal so stator flux control with constant reference is not possible; therefore, indirect stator flux control is performed by controlling the flux-related d-axis current using hysteresis control, which provides acceptable control of time-varying signals. Hence BLDC motor operates in the fluxweakening region by properly selecting the d-axis current reference.

The vector control method in the $\alpha \beta$ plane provides the trajectory of supply current which resembles the petal of a flower explained by Buja et al. [10] to minimize torque undulation of a BLDC motor. The vector control method is based on the internal product of the phase back-emf vector by the phase current vector, which has to be injected into the motor to maintain constant projection over the phase back-emf vector. The major drawback is that backemf will not be constant during commutation for the phase of outgoing current which reduces torque performance and affects the stability.

Fang et al. [11, 12] provided an instantaneous and increased torque control for BLDC motor with less inductance to improve torque estimation. Instantaneous torque estimation improvement is achieved by back emf estimation. Increased torque control by reducing current ripple during the commutation and conduction regions through active controllers. Unbalance in three-phase winding is solved by the asymmetric compensation function; hence commutation ripple is reduced by phase control. The disadvantage of the above method will move the poles, hall sensors, and rotor position when accelerated torque and sudden increase in current which leads to torque undulation.

Goswami and Joshi [13] presented a performance review on a fuzzy controller applied to BLDC motor to improve only the dynamic performances. PI and Proportional Integral Derivative (PID) controllers are normal because of simple structure and robust operation. Nowadays manual controllers are replaced by artificial controllers because of large overshoot and settling time. One such controller is the fuzzy controller to monitor the parameter variations of the BLDC motor during dynamic conditions. But on steady-state performance, the fuzzy controller is not suitable.

To control the BLDC motor under steady-state and transient conditions Navaneethakkannan and Sudha [14] developed an Adaptive Neuro-Fuzzy Interference System (ANFIS) which resolves the 
nonlinearities and mitigates the torque ripple and provides high starting torque. ANFIS controller reduces the settling time and increases the rotor position by selecting the suitable controller using the learning algorithm. The dynamic response of different input data is trained to reduce the torque undulation. The only drawback is the data interpretation where the response time will be more.

Gowtham and Kumar [15] discussed the design of the SEPI converter-based BLDC motor for photovoltaic (PV) applications. An enormous amount of power can be obtained from Perturb and Observe method SEPI converter can be used to increase or decrease the input supply based on the inductance which will vary the output power. The advantage of the SEPI converter is polarity at the output side will be the same as the input side. The characteristic curve for the PV and performance of BLDC motor under varying conditions are simulated.

Vishwanathan and Seenithangom [16] presented a new methodology to suppress the torque undulation by regulating DC supply voltage from the SEPI converter circuit during the turn-off period for low stator winding inductance. The constant voltage control method has been employed to balance the incoming and outgoing phase currents as well as to regulate the input voltage applied to SEPIC. The major drawback is the use of low stator winding inductance of the BLDC motor which produces torque undulation. Dynamic parameters like speed, current, back emf, torque are analyzed and fractionalorder proportional-integral-derivative controller for generating pulse to the inverter.

Hybrid techniques [17] involve adaptive NeuroFuzzy and firefly algorithm to reduce the computation time, harmonics, and torque ripple. The finite algorithm method is used to analyze the change in functions to acquire the maximum gain value. This maximum gain value regulates the speed and Fraction Order Proportional Integral Derivative Controller (FOPID) to reduce the torque undulation. FOPID controller controls peak overshoot, steady-state error, settling time, and rise-time, but does not regulate the delay time which is a major drawback in this method.

Kumar and Chockalingam [18] developed a controller for a BLDC motor for an electrical vehicle. PID and FOPID are used for tuning the parameters of the BLDC motor and also to obtain stability. The changes obtained by the PID controller are replaced by FOPID Controller. FOPID controller is much more effective in controlling the speed of the BLDC motor, but not concerning torque undulation.

Diofode and Suryawanshi [19] designed a PV fed bridgeless single switch SEPI converter for BLDC motor. PI controllers are used for the implementation of the converter which offers a high dynamic and transient response during its operation and Arduino platform is used for the hardware implementation. The proposed method is much more effective to control PV-fed systems for low-power BLDC motors. Hence the above method cannot control steady-state response as well to a high-power BLDC motor.

Despande et al. [20] conducted a study on BLDC drive using a diode bridge rectifier and SEPI converter. Diode bridge rectifier with high value of capacitor produces low power factor and harmonics. The SEPI converter-based BLDC drive provides less distortion compared with the bridge rectifier. SEPIC operates in discontinuous conduction mode with one voltage sensor to control the voltage and speed of low-power BLDC motor. Hence, to control high power BLDC motor the above technique fails with SEPIC in discontinuous mode.

Ramkumar et al. [21] validated the performance of solar PV-based SEPI converter for water pumping BLDC motor. The overall system reduces the highfrequency switching losses by minimizing the inverter switches and components in the sensor system. SEPIC is used in between DC-DC converter to attain maximum efficiency as well as to provide the smooth start of BLDC motor. The incremental size used in the Maximum Power Point Tracking (MPPT) algorithm is small to obtain a smooth start of the BLDC motor. High duty ratio control with a larger incremental size tracking algorithm tends to oscillate which will make the motor vibrate creating oscillations in torque hence smooth operation cannot be achieved.

Vinatha [22] provided a Field Programmable Gate Array (FPGA) based digital controller for BLDC motor. The Xilinx system oscillator is used in the FPGA controller to generate the switching pulse for SEPIC and Voltage Source Inverter (VSI). The completion of setup is investigated under varying operating voltages to provide less Total Harmonic Distortion (THD) and unity power factor. FPGA controller provides switching pulse to the bridgeless SEPIC and commutation logic to the voltage source inverter. Hence, fault in the FPGA controller affects the whole system of operation. 
Senthilnathan and Palanivel [23] introduced an Outgoing-Phase Current Discharge Hysteresis Control (OCDHC) to reduce torque ripple while requiring less response time. To create a gate pulse for inverter BLDC motors utilizing OCDHC control, digital controllers such as Xilinx ISE and IMPACT tools are incorporated in FPGA controllers. OCDHC has a fast response time and good performance. The use of an FPGA in conjunction with OCDHC enhances response speed and performance.

Kavin and Subha [24] proposed a novel interleaved SEPI converter which operates at a low duty cycle. The inverter used in the novel technique provides low switching losses and is cost-effective. The excess power from the solar panel is transferred to a singlephase grid through bidirectional power flow during the daytime and during the night time, the grid supplies power to BLDC fed electric vehicles. The advantage of the above method is the wastage of power is well utilized whereas more switching elements and lumped components are used in interleaved and grid side converters which produce more switching stresses and undulation in torque.

Yao et al. [25] proposed an auxiliary step-up circuit to minimize torque undulation of BLDC Motor. The auxiliary setup circuit consists of a capacitor, transformer, and switch circuit. The capacitor is charged during the non-commutation period. The advantage of the above method is partial energy will be transferred during the commutation process and the remaining energy returned to the power supply during each cycle to improve the energy efficiency. Switches, transformers, and capacitors are used in the auxiliary circuit which makes the circuit heavy and produces more switching stress across the devices.

Cao et al. [26] designed a semiconductor-assisted step-up inverter circuit for mitigating the torque undulation. Parallel charging and series discharging of capacitors in the diode capacitor network provide a control for the motor. Switching vectors are arranged in sequence during the commutation and conduction periods to reduce the switching stress and distortion. The drawback is the above-designed circuit operates in a low voltage source and less speed.

Knypinski et al. [27] suggested a cuckoo search algorithm based on finite element method using lumped parameters to minimize the torque undulation in BLDC motor. Cuckoo search algorithm coupled with static penalty function utilizes optimization value to minimize the torque pulsation. During the commutation period, the magnetic circuit gets saturated. More number iterations are needed to obtain an optimum value which increases the time as well the circuit gets saturated.

Huang et al. [28] recommended open-end winding in BLDC motor reduces the torque ripple by overlapping the commutation with turn off phase applied voltage and delayed turn off. Open-end winding provides a wide range of speed control under low voltage and large currents. To reduce torque undulation overlapping commutation with phase current control is proposed in the above method. The merits of the above method involve commutation taking place during the turn-off of phase current which makes electromagnetic torque constant. Drawbacks of the above method involve mutual inductance in phase winding affects the current during the non-commutation period, which produces more torque undulation and operation is continuous which may overheat the motor reducing the efficiency and performance of the system.

The literature review discussed the performance of BLDC motor with conventional 3-level inverter without converter has been analyzed where switching losses are very less, a wide range of speed control, petal designed trajectory in supply current, choosing less inductance in BLDC motor. When the converters are added along with BLDC motor switching stress is reduced by generating a pulse through digital controllers as well as maintaining stability in the drive. Many algorithms have been implemented to reduce the torque distortion and commutation overlap. Three-level inverters provide a common point that creates a commutation overlap because of the circulating current in the BLDC motor. Normally open-end winding has no neutral point which is electrically isolated with a wide range of speed control, large voltage, and low current applications of BLDC motor. Mutual inductance between the phase windings affects the commutation interval even though open-end winding is used in a BLDC motor. Any fault in one phase affects the mode of operation in a common point diode clamped inverter. By providing additional switches in the dc-link the commutation problem associated with open-end winding is resolved. This paper deals with an improved model of the 3-LCEDC inverter along with SEPI converter to reduce the commutation overlap, switching stress, voltage balance, low switching frequency and less undulation. 


\section{Methods}

3.1Modelling of BLDC drive system

The conventional three-phase 3-LCEDC inverter BLDC motor is indicated in Figure 1. Metal Oxide Semiconductor Field Effect Transistor (MOSFET) is used as a switching device to operate the diode clamped inverter. The Pulse Width Modulation (PWM) controller produces firing signals for the 3LCEDC. Three levels operate in $120^{\circ}$ conduction mode where two switching devices are in conduction, one in the top group and another in the bottom group. During Mode $\mathrm{I} \quad \mathrm{Q}_{1}$ and $\mathrm{Q}_{6}$ are in conduction the supply voltage flows through the A-phase and B phase where Id is positive in phase A. During Mode II $Q_{1}$ and $Q_{2}$ are turned on and $Q_{6}$ is turned off. The supply voltage flows through phase A and phase $\mathrm{C}$. The output voltage is obtained by changing the mode of operation.

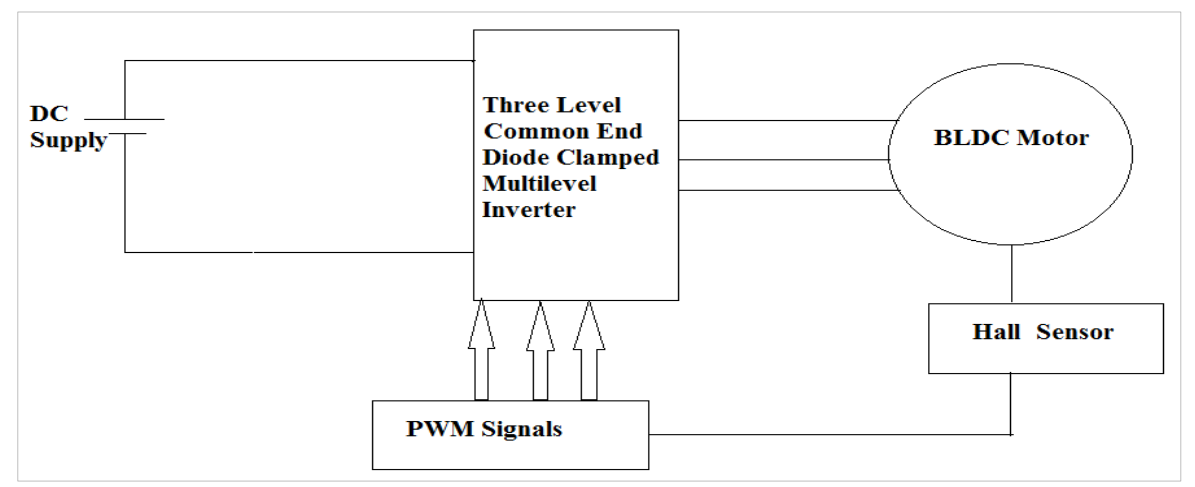

Figure 1 Three-level inverter fed BLDC motor

Stator voltages of the BLDC motor are shown in Equation 1, 2 and 3.

$$
\begin{aligned}
& V_{a}=R_{a} I_{a}+\left(L_{s}-M\right) \frac{d i_{a}}{d t}+e_{a} \\
& V_{b}=R_{a} I_{b}+\left(L_{s}-M\right) \frac{d_{b}}{d t}+e_{b} \\
& V_{c}=R_{a} I_{c}+\left(L_{s}-M\right) \frac{d_{c}}{d t}+e_{c}
\end{aligned}
$$

$I_{a}, I b, I_{c}$ - armature Current of three phases

$\mathrm{e}_{\mathrm{a}}, \mathrm{e}_{\mathrm{b}}, \mathrm{e}_{\mathrm{c}}$ - back- emf of BLDC motor for $120^{\circ}$ mode.

$\mathrm{L}_{\mathrm{s}}$-Self Inductance in Henry

M-Mutual Inductance in Henry

$\mathrm{R}_{\mathrm{a}}$-Armature resistance $\Omega$

The instantaneous torque generated by the BLDC motor are expressed in Equation 4.

$T_{e}=\frac{e_{a} I_{a}+e_{b} I_{b}+e_{c} I_{c}}{\omega_{m}}$

The Torque expressed in machines is shown in Equation 5.

$T_{e m}=J \frac{d \omega_{m}}{d t}+B \omega_{m}+T_{l}$

$\mathrm{J}, \mathrm{B}$, and $\omega_{\mathrm{r}}$ represent the inertia of the motor, damping coefficient, and angular frequency vector, of the motor. $\mathrm{T}_{\mathrm{L}}$ is the torque produced by load. The counter-emf and the current waveform are exhibited in Figure 2 where the counter-emf and the current waveform are trapezoidal and rectangular for positive and negative cycles.

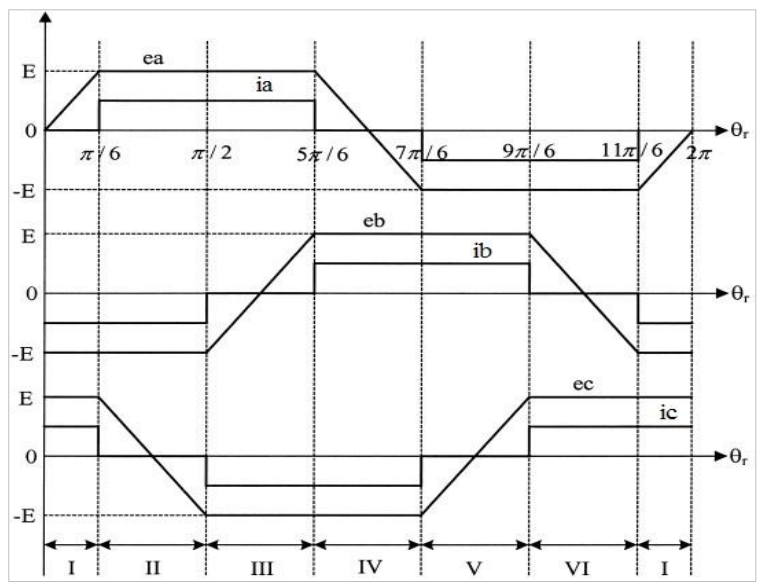

Figure 2 Counter-EMF and current waveform of BLDC motor

\subsection{Modified topology of BLDC drive system}

The Conventional 3-LCEDC inverter produces large back emf and unstabilized voltage which creates more undulation in current and torque. Hence the proposed modified SEPI converter with Three Level Common End Diode Clamped Inverter (3-LCEDCI) fed BLDC motor produces less torque undulation and constant voltage as expressed in Figure 3. In this 
method, modified SEPIC is implemented and 3LCEDCI is suggested to minimize the torque distortion, based on the revolving speed of BLDC motor. The SEPI converter is built with power $\operatorname{MOSFET}_{\mathrm{s}}\left(\mathrm{S}_{1}\right)$ to maintain a constant dc-bus voltage, 3-LCEDC for torque ripple improvement during the turn-off period. The speed sensors are electronically commutated by the inverter switches. PWM generator is used to generate pulse signals for 3LCEDC.

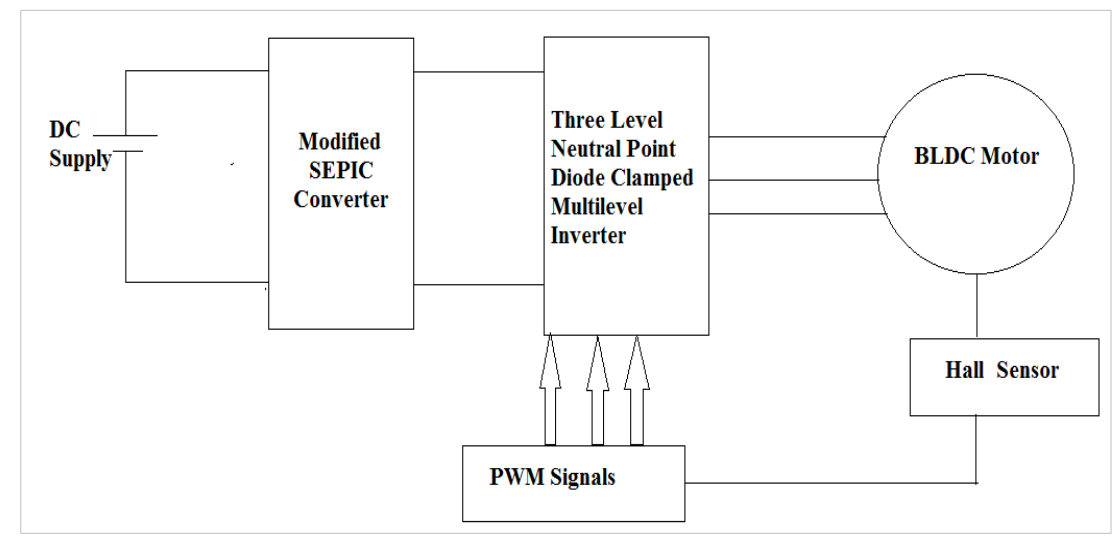

Figure 3 Improved converter method for BLDC motor

\subsubsection{Modified SEPIC operation}

The conventional SEPI converter is replaced by modified SEPIC with additional diodes and filters. Additional series Resistor Inductor (RL) and Resistor Capacitor (RC) circuits are provided to obtain stabilized output voltage. SEPIC provides either high or low-level output voltage unlike step up or step down converter. Buck-boost converter provides an output voltage increase or decreases concerning ground, unlike SEPI converter. The modified SEPIC provides variable dc to a fixed output voltage as depicted through Figure 4.

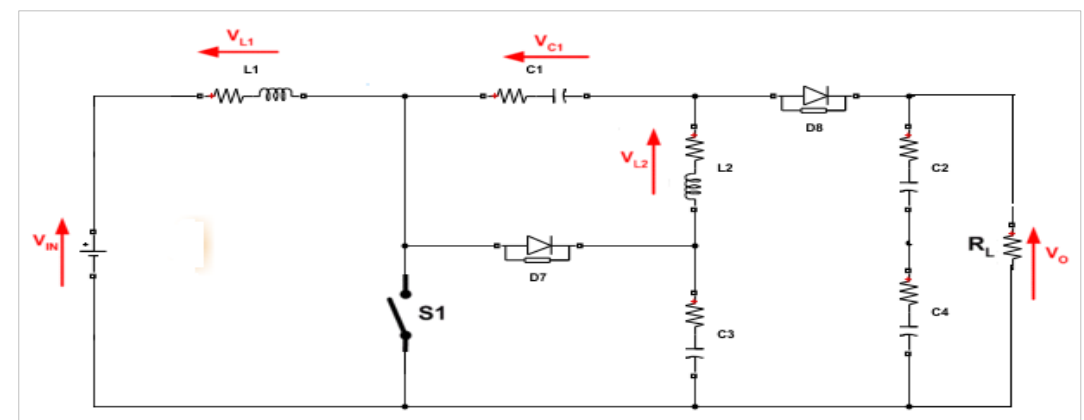

Figure 4 SEPI converter circuit

Voltage is transferred from one level to another through a SEPI converter. The output voltage is controlled by a switch $\mathrm{S}_{1}$, which is a MOSFET controlled by a change in voltage between the inductor and capacitors as shown in Equation 6. A SEPI converter operates in Continuous Conduction Mode (CCM).

$\mathrm{V}_{\mathrm{IN}}=\mathrm{V}_{\mathrm{L} 1}+\mathrm{V}_{\mathrm{c} 1}+\mathrm{V}_{\mathrm{L} 2}$

The windings used in the inductors are of the same core, hence the voltage remains the same in magnitude and the mutual inductance becomes zero. The ripple current between the two inductors will be of the same magnitude. Two modes of operation are explained below.

\section{Mode I (Switch $\mathrm{S}_{\mathbf{1}} \mathrm{ON}$ )}

During turn-on of switch $\mathrm{S}_{1}$, current $\mathrm{I}_{\mathrm{L} 1}$ increases and $\mathrm{I}_{\mathrm{L} 2}$ decreases which depend on a positive supply voltage is displayed in Figure 5. The inductor voltage $\mathrm{V}_{\mathrm{L} 1}$ will be equal to the supply voltage and $\mathrm{V}_{\mathrm{L} 2}=$ $-\mathrm{V}_{\mathrm{Cl}}$. Therefore, the capacitor $\mathrm{C}_{1}$ raises the current 
value of inductor $\mathrm{I}_{\mathrm{L} 2}$ and the energy in the inductor also increases.

\section{Mode II (Switch $\mathrm{S}_{\mathbf{1}}$ OFF)}

During the turn-off switch, the inductor current flows toward load resistance $\mathrm{R}_{\mathrm{L}}$. The inductor current $\mathrm{L}_{2}$ will flow in the negative direction. Using Kirchhoff's current law, the diode current can be written as $\mathrm{I}_{\mathrm{D} 1}=$
$\mathrm{I}_{\mathrm{C} 1}-\mathrm{I}_{\mathrm{L} 2}$. Capacitor $\mathrm{C}_{1}$ and $\mathrm{L}_{2}$ get charged during Mode I operation as displayed in Figure 6. The operation of the SEPI converter depends on the passive elements which produce an output voltage of step-up based upon duty cycle $S_{1}$. The output voltage $\left(\mathrm{V}_{\mathrm{O}}\right)$ is equal to $\mathrm{V}_{\mathrm{S} 1}-\mathrm{V}_{\mathrm{IN}}$.

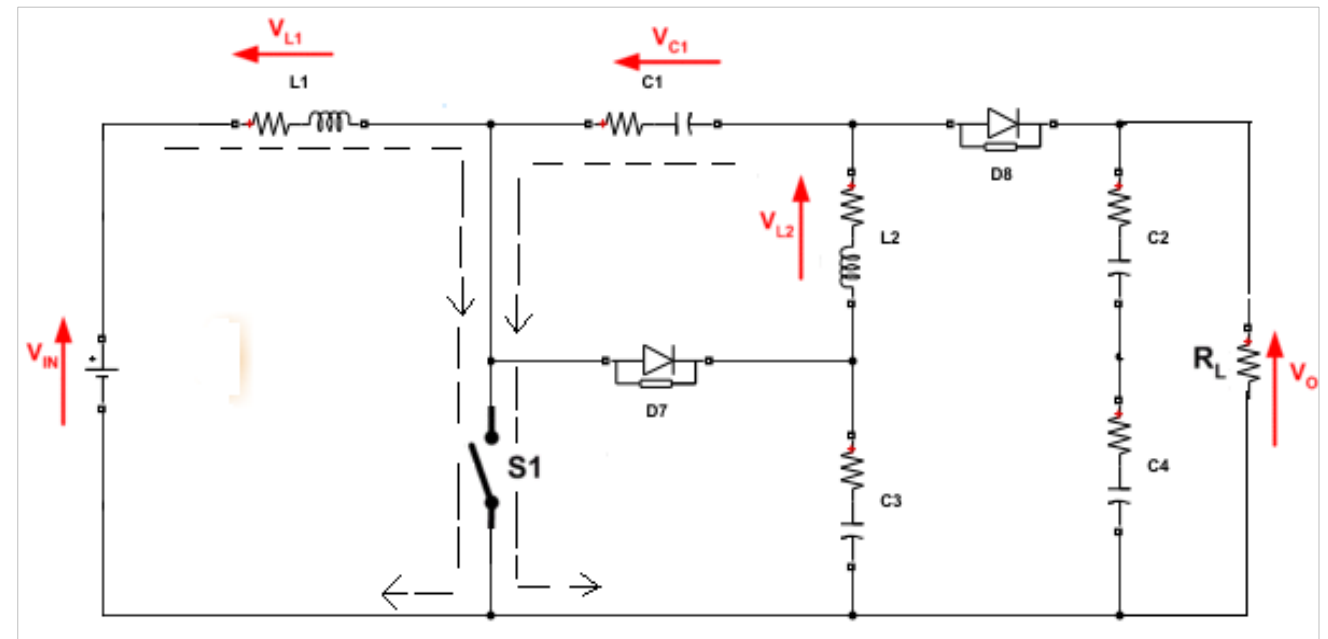

Figure 5 SEPI converter with switch $\mathrm{S}_{1} \mathrm{ON}$

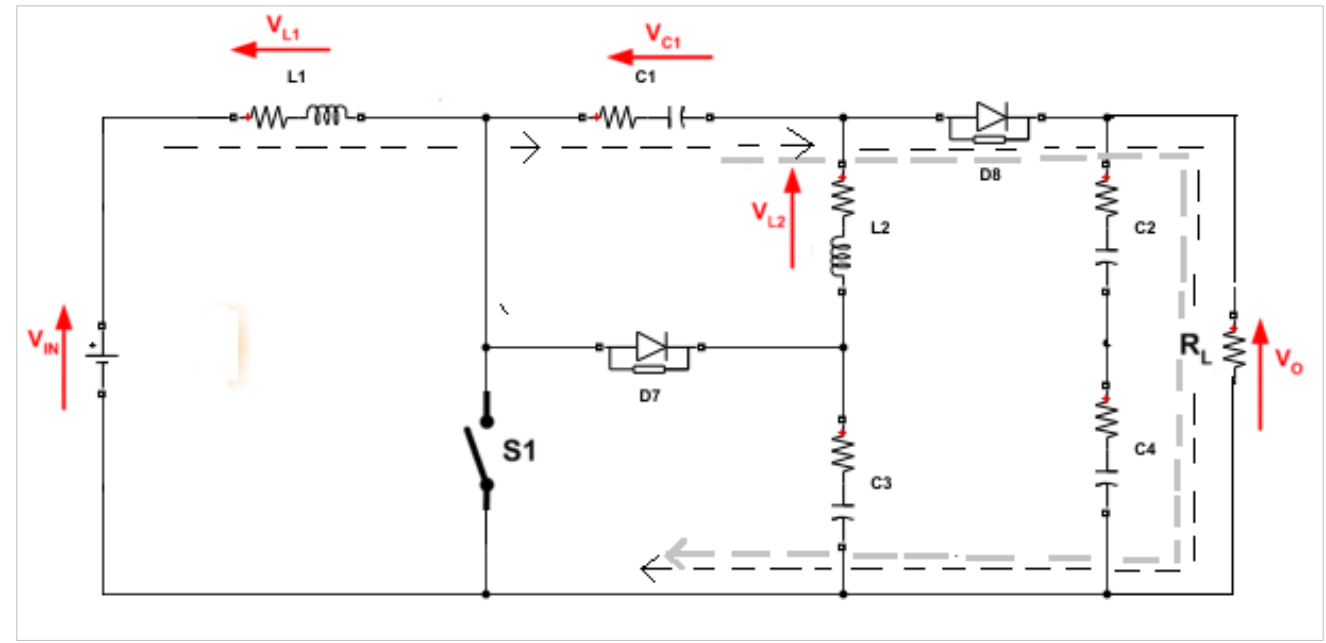

Figure 6 SEPI converter with switch $\mathrm{S}_{1} \mathrm{OFF}$

3.2.2Three level common end diode clamped inverter (3-LCEDCI)

Diodes are used to clamp various steps in the output voltage hence called diode clamped multilevel inverters. To obtain a different level of output voltages capacitors can be added in addition to dclink capacitors. The floating-point provides the common point of the dc bus, hence called Common End Diode Clamped Inverter (CEDCI). The circuit model of a 3-LCEDC inverter is displayed in Figure 7. Each limb includes four switches within built diodes. Four switches are added in the dc link to avoid commutation overlap. The capacitor divides DC input into two voltages as well as provides common end $\mathrm{Z}$. The clamp diodes are connected between the top and bottom legs. The voltage applied to link capacitors is E. Table 1 shows the switching states and output voltage levels of one phase. The 
output equals $\mathrm{V}_{\mathrm{d}}$ volt whenever the upper switches are active and zero volt whenever the lower switches are active. When one switch from the upper and lower leg conducts the output is $\mathrm{V}_{\mathrm{d}} / 2$.

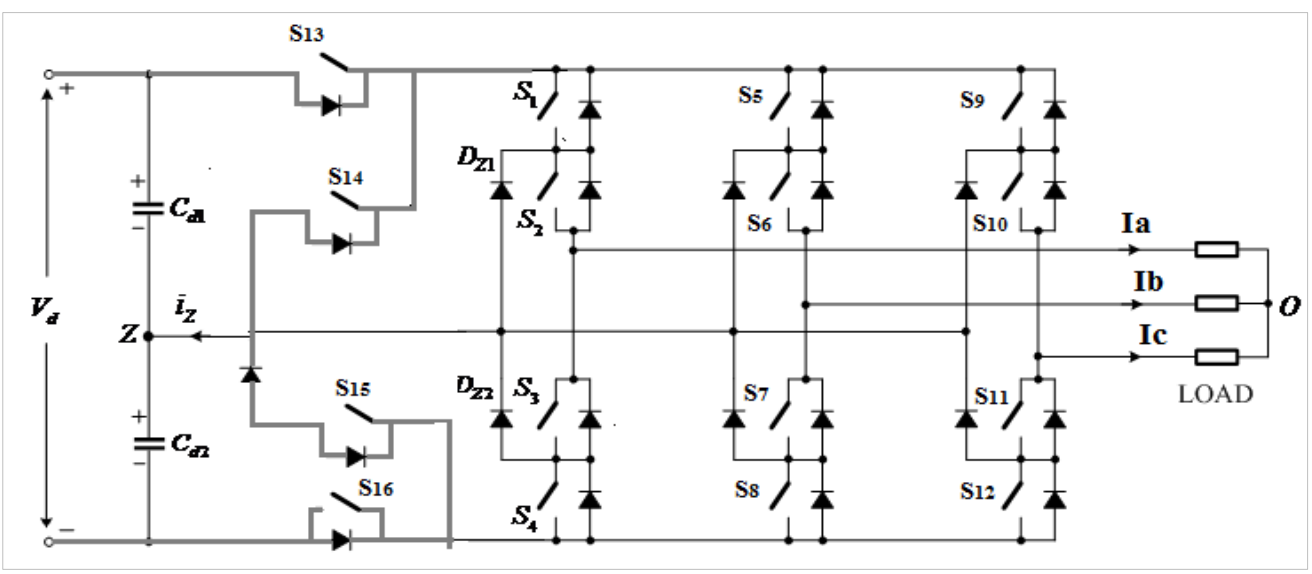

Figure 7 Three-level common end diode clamped inverter

The operation of a 3-LCEDC inverter for phase A leg is considered [29-31]. The speed and torque are used to generate pulses for the diode clamped inverter by using logic circuits. The steps to obtain three levels are as follows. Logic" $1^{\text {ce }}$ and logic "0" indicate ON and OFF. There are two complementary switches in each leg $\left(S_{1}, S_{3}\right)$ and $\left(S_{2}, S_{4}\right)$. Thus, if the top corresponding pair switch is turned $\mathrm{ON}$, then the bottom pair must be OFF. The output voltage will be obtained when pair of switches conduct together. Trapezoidal back emf produced by BLDC motor is used to produce PWM pulse for the four switches in addition to diode clamped inverter.

Table 1 Switching sequence and voltage levels

\begin{tabular}{lllll}
\hline $\begin{array}{l}\text { Switch number/ } \\
\text { voltage }\end{array}$ & $\mathbf{S}_{\mathbf{1}}$ & $\mathbf{S}_{\mathbf{2}}$ & $\mathbf{S}_{\mathbf{3}}$ & $\mathbf{S}_{\mathbf{4}}$ \\
\hline 0 & 0 & 0 & 1 & 1 \\
\hline$+\mathrm{V}_{\mathrm{d}} / 2$ & 0 & 1 & 1 & 0 \\
\hline$+\mathrm{V}_{\mathrm{d}}$ & 1 & 1 & 0 & 0 \\
\hline
\end{tabular}

\section{Results}

4.1Simulation circuit and results

The simulation circuit of the proposed SEPIC and 3LCEDC inverter fed BLDC drive system is simulated using MATLAB for a switching frequency of $5 \mathrm{kHz}$ is delineated in Figure 8 and results are presented. The proposed SEPI converter employs one switch with a DC voltage of $75 \mathrm{~V}$.

LC filters are added in SEPIC and 3-LCEDC inverter to maintain a constant voltage. Figure 9 and Figure 10 show SEPIC output voltage for the amplitude of 200 volts and the current of 7 amps. Table 2 lists the parameters used in the simulation circuit of the BLDC motor. Figure 10 and Figure 11 present the three-phase and phase A voltage of 3-LCEDCI for 5 $\mathrm{kHz}$ switching frequency. The current waveform for three phases is depicted in Figure 12 where load torque is applied from $0.5 \mathrm{sec}$ to $0.65 \mathrm{sec}$. The output current of a BLDC motor decreases when a load torque is applied, then increases when no load is applied. Stator back emf of BLDC motor is depicted in Figure 13 which resembles trapezoidal curve.

Speed waveform is exhibited in Figure 14 for a speed of $1000 \mathrm{rpm}$ under steady-state. The speed progressively climbs for 0.5 seconds before stabilising at $1000 \mathrm{rpm}$. When the torque of $1.5 \mathrm{Nm}$ is applied at $0.65 \mathrm{sec}$ and rated load of $2 \mathrm{Nm}$ applied at $0.75 \mathrm{sec}$ the speed remains the same as shown in Figure 15, with a small overshoot when a sudden change in load is applied. Figure 16 shows the electromagnetic torque waveform under no load, partial and full load torque delivered at different times, and load torque applied from 0.5 to 0.65 seconds. Torque ripple is shown in Figure 17 during the equilibrium condition.

Table 2 Parameters used in the simulation circuit of BLDC motor

\begin{tabular}{ll}
\hline Operating Specifications & Values \\
\hline Stator Phase Resistance & $0.18 \Omega$ \\
\hline Resistance $(\mathrm{Ph}-\mathrm{Ph})$ & $0.36 \Omega$ \\
\hline Armature Inductance & $0.000835 \mathrm{H}$ \\
\hline Armature Inductance $(\mathrm{Ph}-\mathrm{Ph})$ & 1.67 \\
\hline $\begin{array}{l}\text { Flux linkage induced by the } \\
\text { magnet }\end{array}$ & 0.175 \\
\hline
\end{tabular}


International Journal of Advanced Technology and Engineering Exploration, Vol 8(85)

\begin{tabular}{ll}
\hline Operating Specifications & Values \\
\hline Voltage Constant & 44.8867 \\
\hline Torque Constant & 0.428536 \\
\hline Proportional Gain & 5 \\
\hline Integral Gain & 10 \\
\hline
\end{tabular}

\begin{tabular}{ll}
\hline Operating Specifications & Values \\
\hline Motor pair of Poles & 2 \\
\hline Switching Frequency & $5 \mathrm{KHz}$ \\
\hline Sampling Time & $20 \mathrm{e}-6 \mathrm{~s}$ \\
\hline Current Hysteresis Bandwidth & 0.01 \\
\hline
\end{tabular}

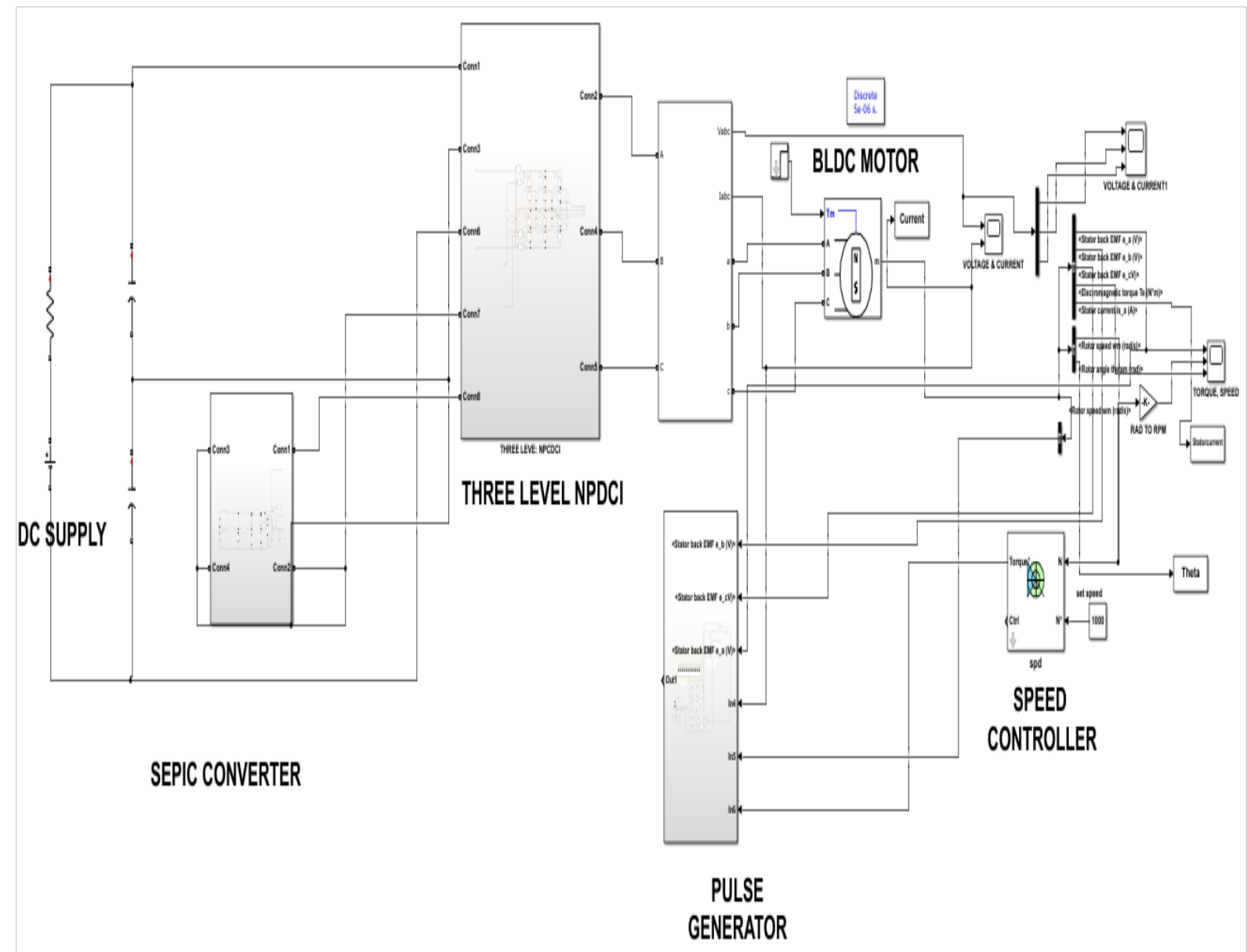

Figure 8 Proposed BLDC motor drive system

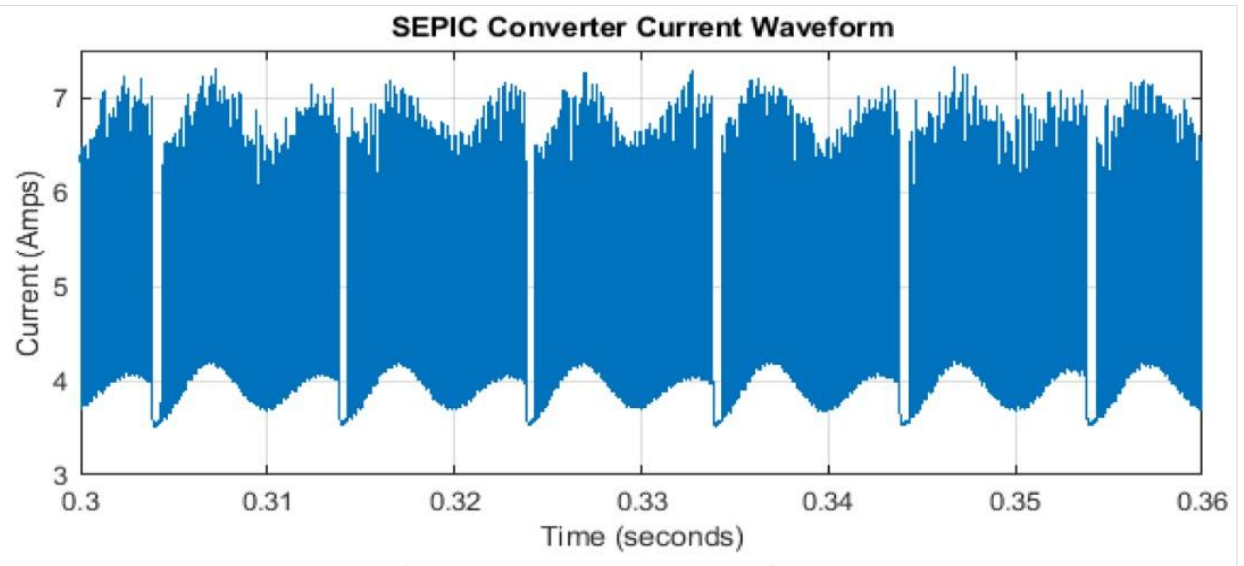

Figure 9 SEPIC current waveform 
Manoj Kumar N et al.

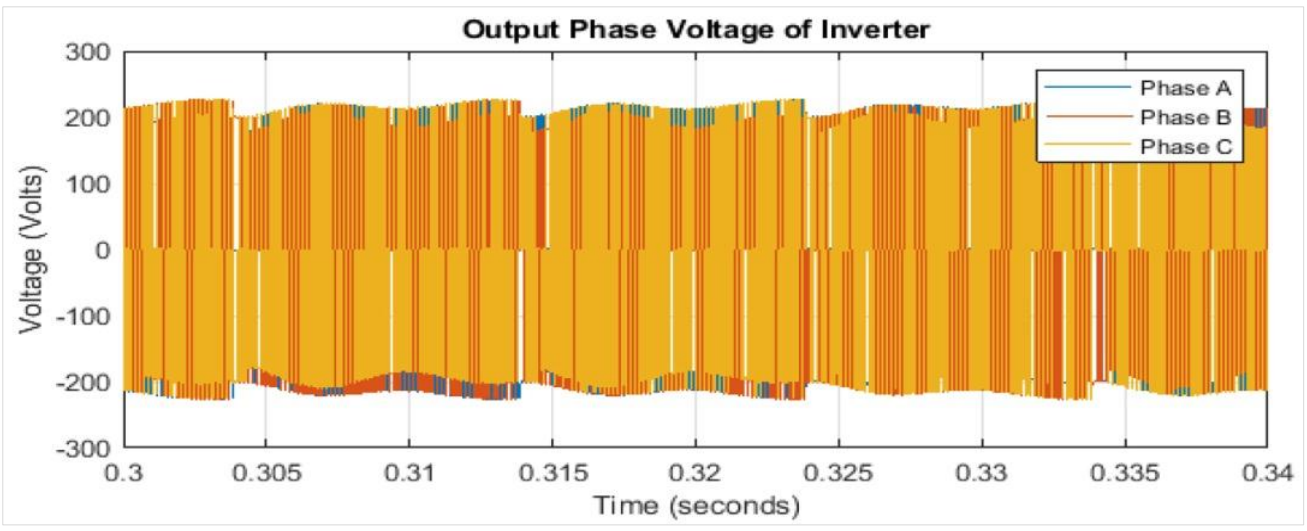

Figure 10 Three phase output of 3-LCEDC

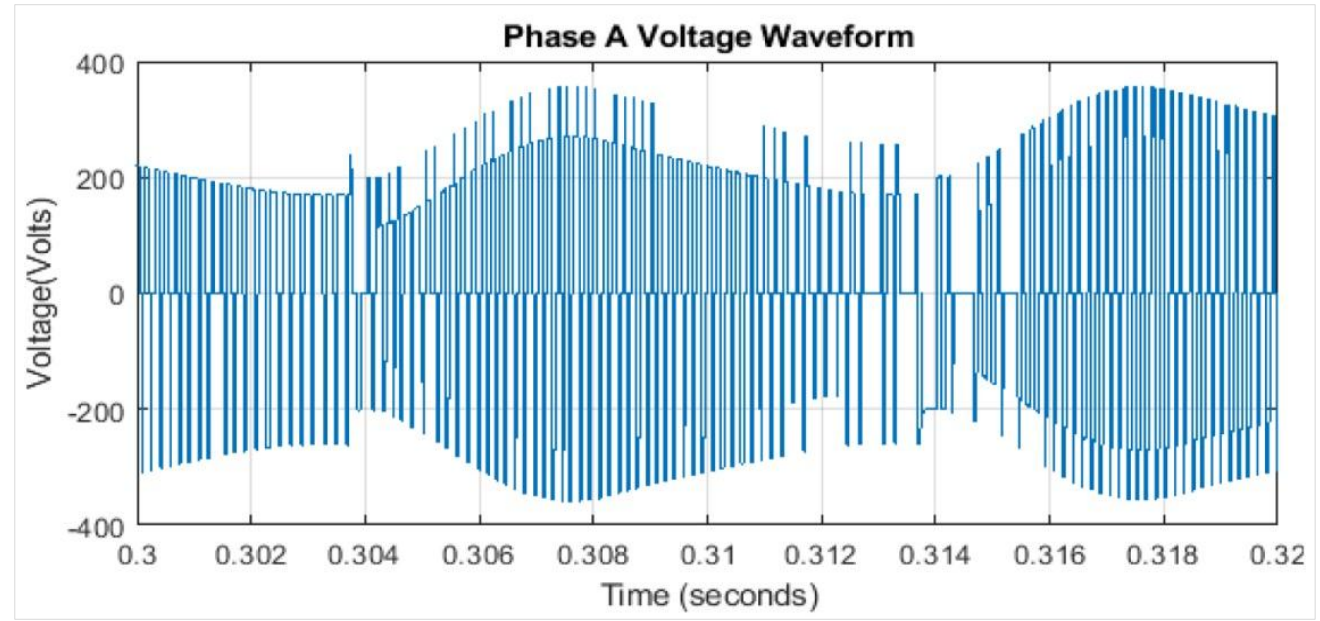

Figure 11 Phase A voltage of 3-LCEDCI

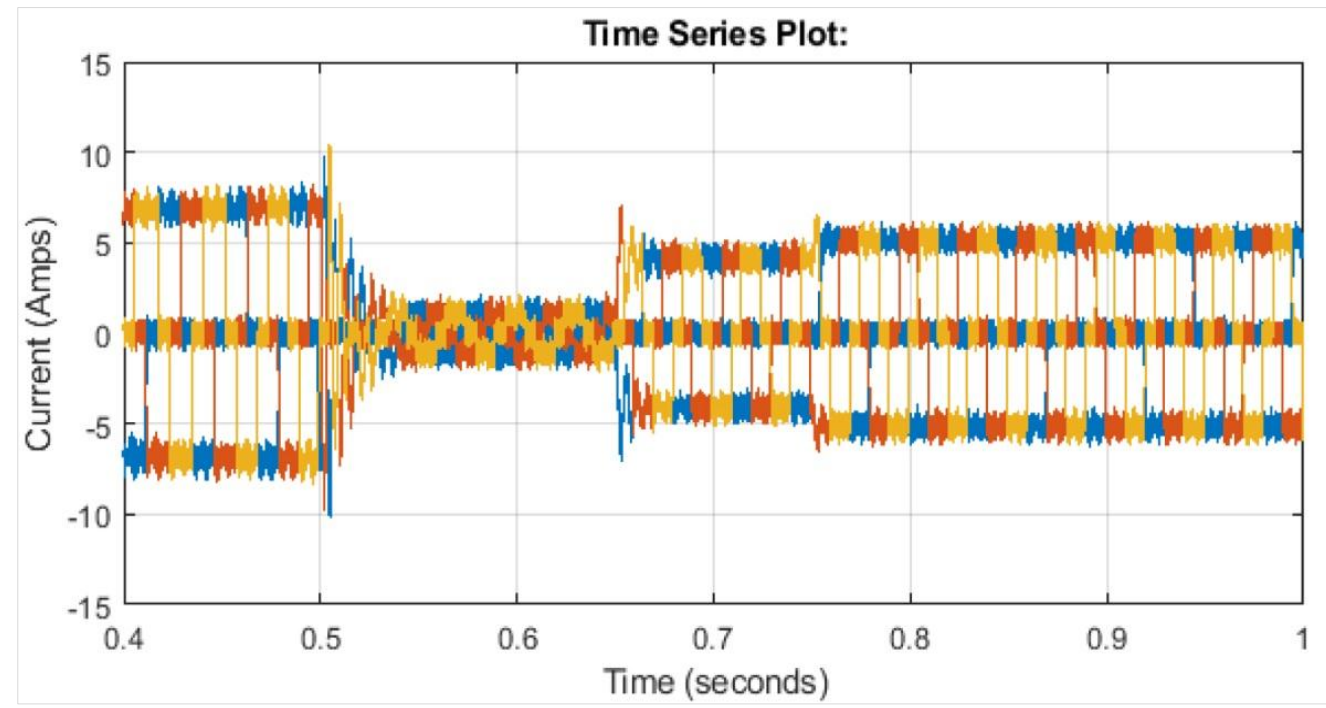

Figure 12 Current waveform of 3-LCEDCI 


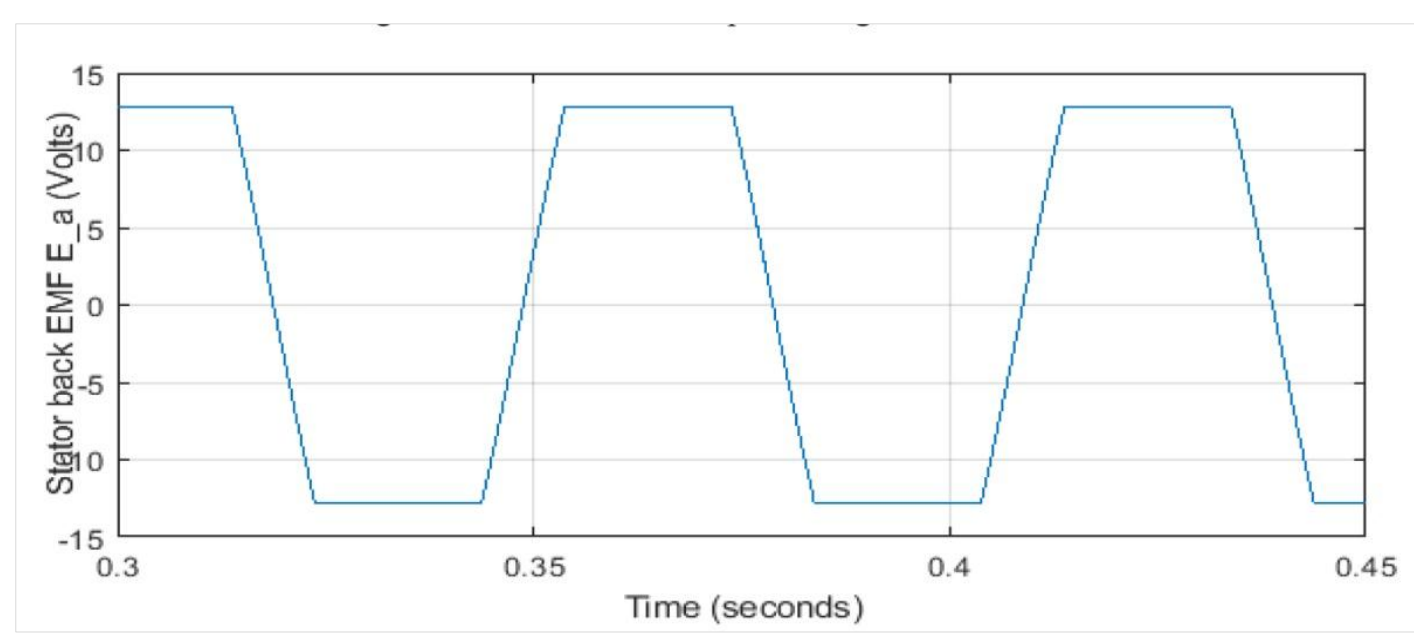

Figure 13 Back EMF of BLDC motor

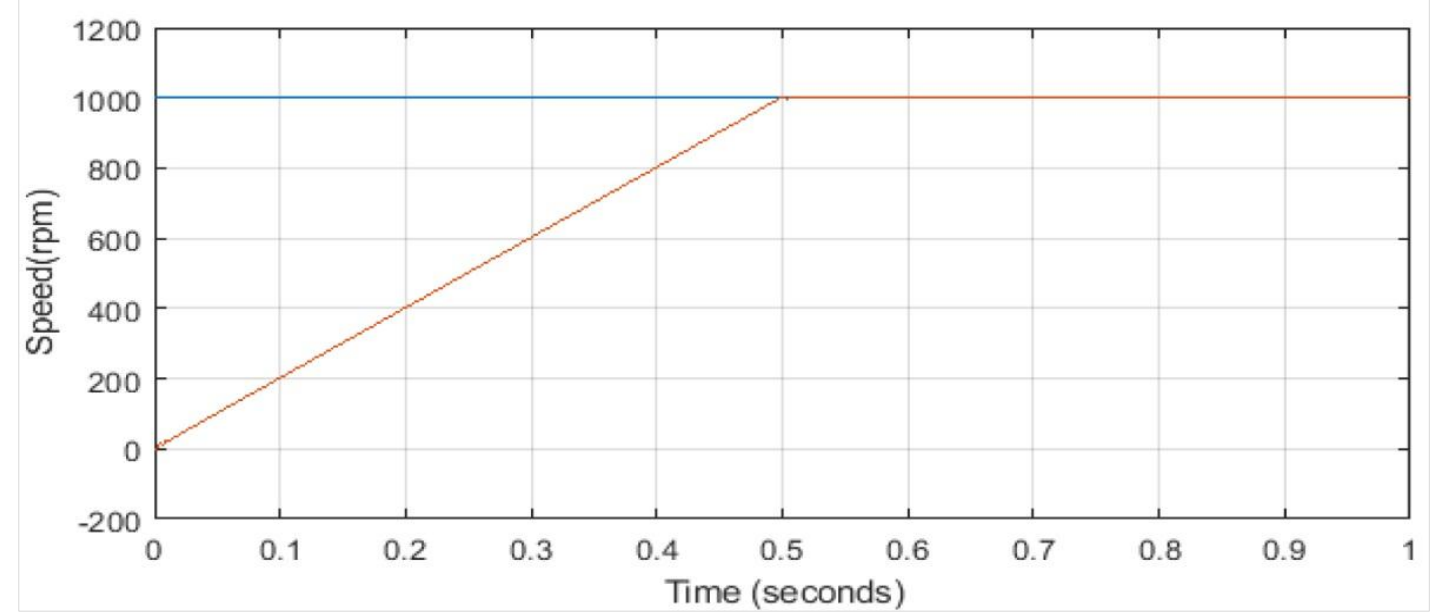

Figure 14 Speed waveform at no load

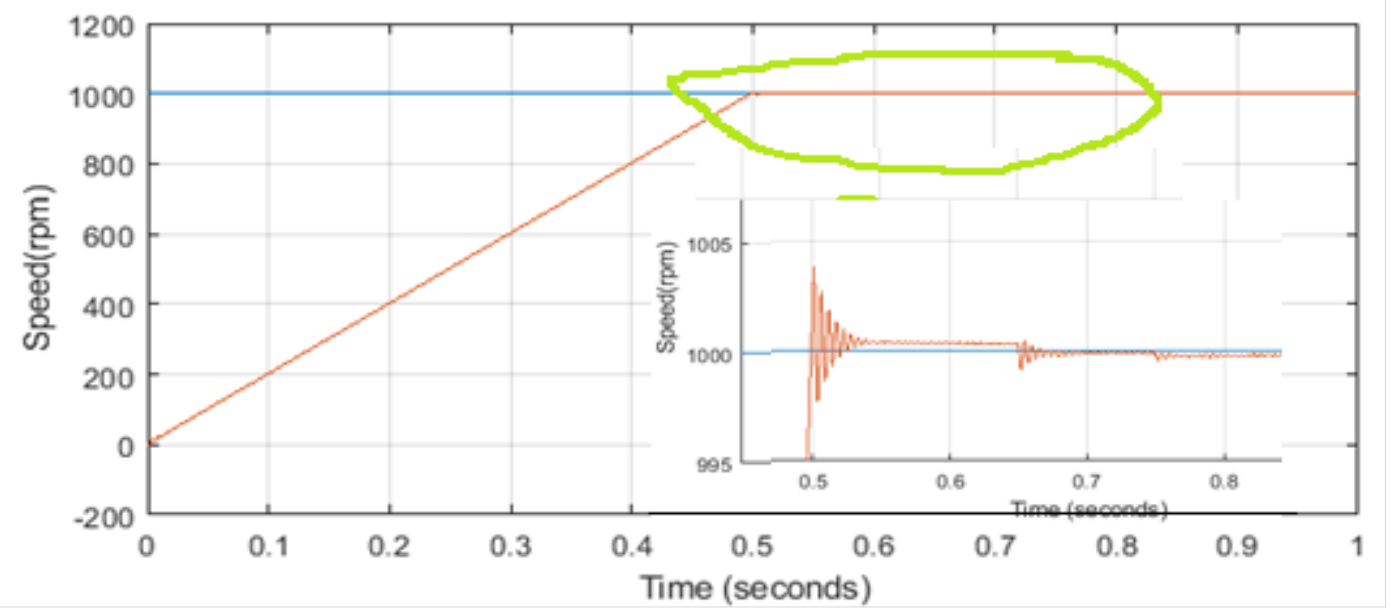

Figure 15 Speed waveform of BLDC motor under load 


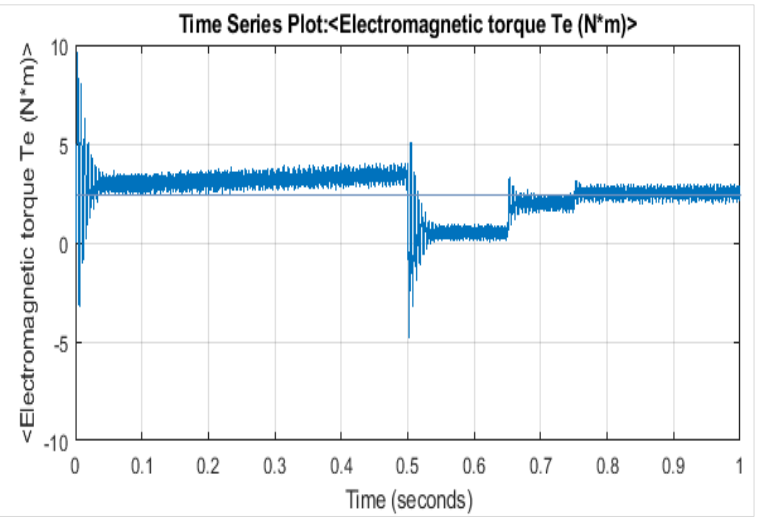

Figure 16 No load and Load period Torque waveform of BLDC motor

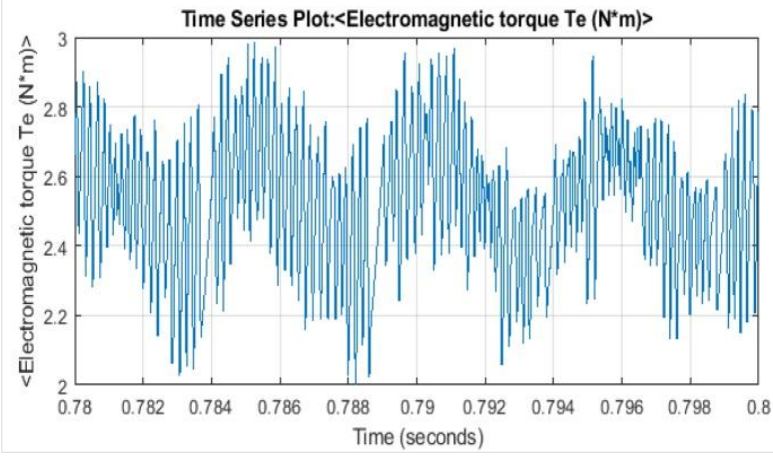

Figure 17 Torque ripple waveform

\subsection{Fuzzy regulator for brushless direct current}

(BLDC) motor

A fuzzy controller is added to the speed controller to smooth the speed response and thereby improve torque undulation with less vibration. Fuzzy Regulator (FR) manipulates input variables to produce a controllable output. Fuzzy logic regulator enhances the execution of BLDC motor. Fuzzy Logic Control (FLC) is designed based on the input obtained from the current controller. The glitch and the modified glitch produced from set speed and reproduced speed are multiplied and fed to the fuzzy block. The controller is modelled to provide the modified crunch value and combined to get the speed. The inputs and modified glitch signals are given to the FLC to create the modified speed as output. The fuzzy component L for glitch and the modified glitch is represented as

$\mathrm{L}=$ [SB, SM, SS, ZZ, HS, HM, HB]

(SB- Small Big , SM-Small Medium , SS - Small Small , ZZ - Zero Zero , HS -High Small , HM High Medium, HB -High Big)
Membership functions of input and output vectors are of triangular type as displayed in Figure 18, Figure 19, and Figure 20 [32]. The conditions to operate FLC are shown in Table 3 for glitch and modified glitch based on rule base [32]. The glitch and modified glitch are divided into seven parts based on vectors of small, medium, and high; produces nine different combinations of output based on rule base.

The simulation referring to a 3-LCEDCIBLDC motor with FLC is executed using MATLAB software. The machine initially begins without load and then applied torque of $1.5 \mathrm{Nm}$ and $2 \mathrm{Nm}$ at 0.65 and 0.75 sec, speed overshoots to small period finally reaches $1000 \mathrm{rpm}$ speed as depicted in Figure 21. The electromagnetic torque waveform under no load, partial and full load torque delivered at different times and torque ripple during steady state are depicted in Figure 22 and Figure 23. Table 4 and Table 5 give the torque and current undulation for different speeds under varying switching frequencies without fuzzy and with the fuzzy controller. Torque undulation is very less when added with a fuzzy controller.

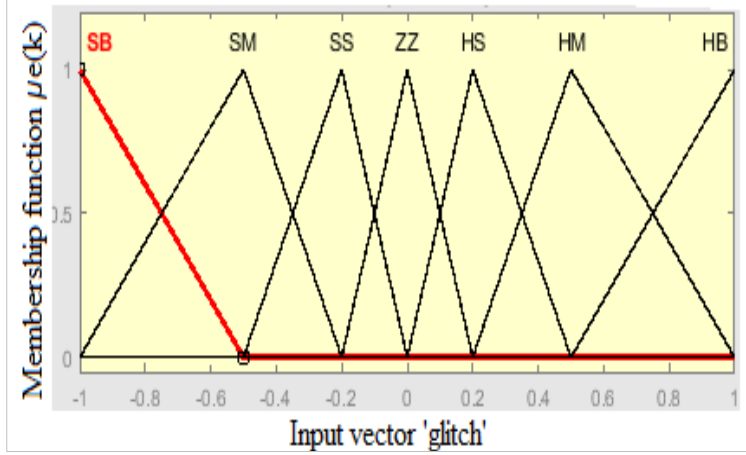

Figure 18 Input vector "glitch"

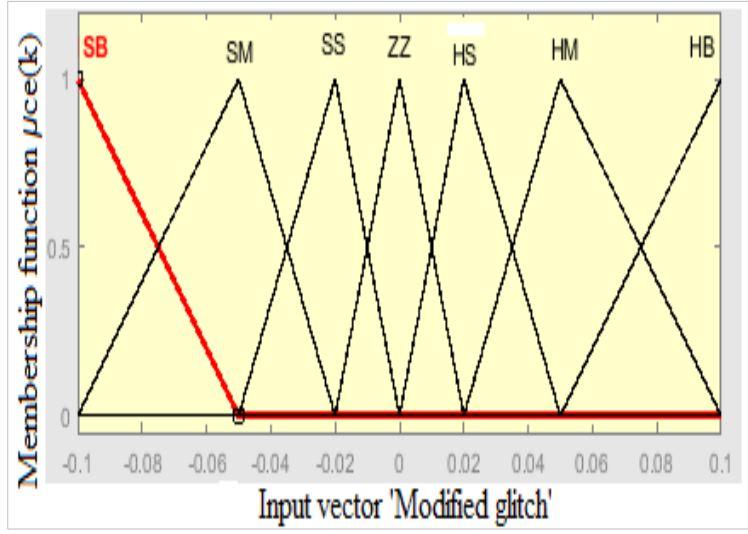

Figure 19 Input vector "Modified glitch" 


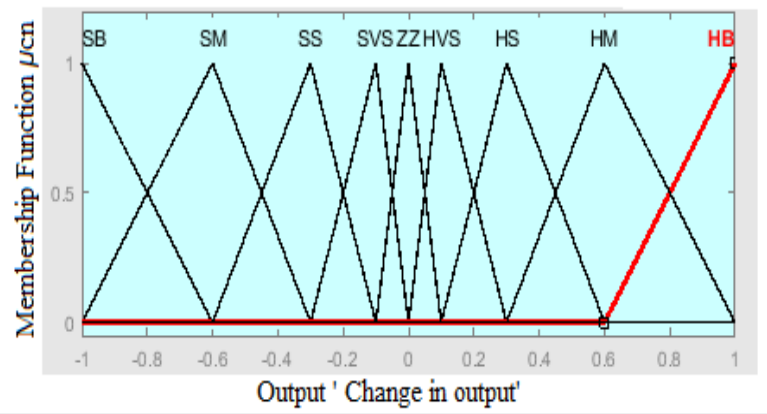

Figure 20 Output vector

Table 3 Rule base of output

\begin{tabular}{llllllll}
\hline G & SB & SM & SS & ZZ & HS & HM & HB \\
\hline MG & & & & & & & \\
\hline SB & SB & SB & SB & SM & SS & SVS & Z \\
\hline SM & SB & SB & SM & SS & SVS & ZZ & HVS \\
\hline NS & SB & SM & SS & SVS & ZZ & HVS & HS \\
\hline ZZ & SM & SS & SVS & ZZ & HVS & HS & HM \\
\hline HS & SS & SVS & ZZ & HVS & HS & LM & LB \\
\hline HM & SVS & ZZ & HVS & HS & HM & HB & HB \\
\hline HB & ZZ & HVS & HS & HM & HB & HB & HB \\
\hline
\end{tabular}

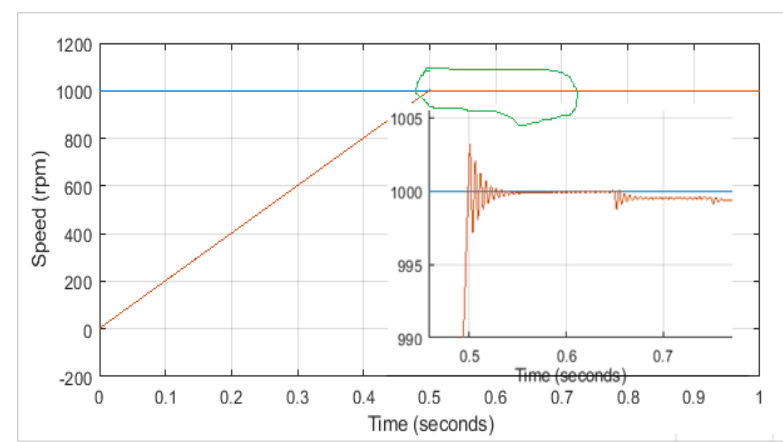

Figure 21 Speed response with fuzzy regulator

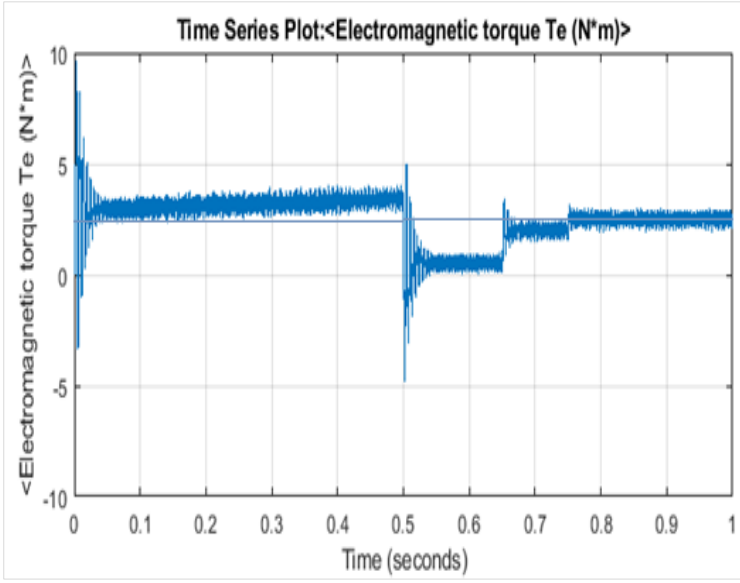

Figure 22 Electromagnetic torque waveform with fuzzy regulator

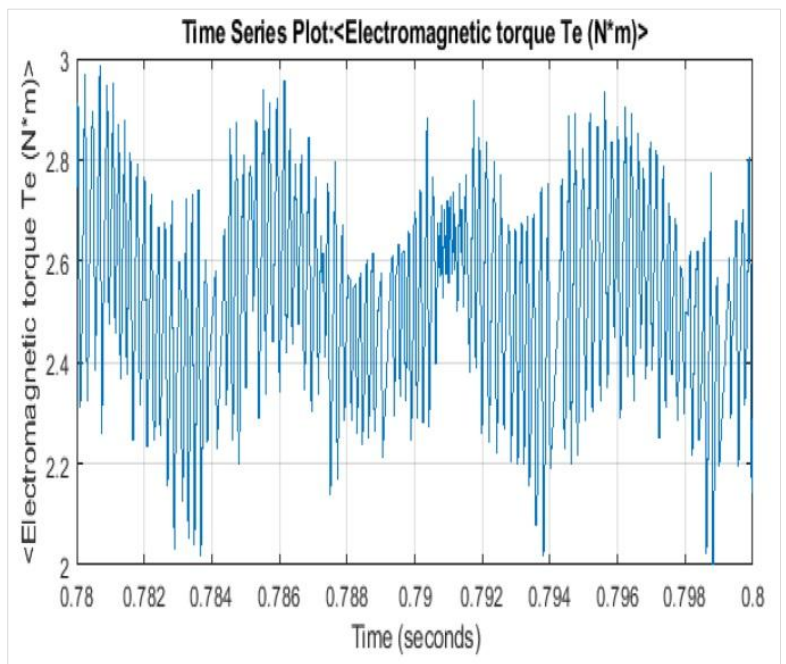

Figure $\mathbf{2 3}$ Torque ripple with fuzzy regulator

Table 4 Comparison of torque undulation

\begin{tabular}{llll}
\hline Switching frequency & Speed & Without fuzzy torque undulation \% & With fuzzy torque undulation \% \\
\hline \multirow{3}{*}{$\mathbf{K H z}$} & $500 \mathrm{rpm}$ & 15.78 & 12 \\
\hline \multirow{2}{*}{$\mathbf{1 0 K H z}$} & $1000 \mathrm{rpm}$ & 12.72 & 11 \\
\hline \multirow{2}{*}{$\mathbf{K H H Z}$} & $500 \mathrm{rpm}$ & 20.22 & 15.55 \\
\cline { 2 - 4 } & $1000 \mathrm{rpm}$ & 16.43 & 12 \\
\hline
\end{tabular}

Table 5 Comparison of current undulation

\begin{tabular}{llll}
\hline Switching frequency & Speed & Without fuzzy current undulation \% & With fuzzy current undulation \% \\
\hline \multirow{5}{*}{$\mathbf{K H z}$} & $500 \mathrm{rpm}$ & 25.35 & 21.75 \\
\cline { 2 - 4 } $\mathbf{1 0 K H Z}$ & $1000 \mathrm{rpm}$ & 18.00 & 15.45 \\
\hline \multirow{2}{*}{$\mathbf{K H Z}$} & $500 \mathrm{rpm}$ & 15.87 & 13.55 \\
\cline { 2 - 4 } & $1000 \mathrm{rpm}$ & 12.5 & 10.78 \\
\hline
\end{tabular}




\subsection{Experimental investigations}

The experimental setup is validated for a BLDC motor with a switching frequency of $5 \mathrm{kHz}$ for 3LCEDC Inverter and SEPIC. The control logic is employed using the SEPIC controller to generate a gate pulse for the converter and inverter. Figure 24 shows the experimental setup of SEPIC with driver circuit and 3-LCEDC Inverter fed BLDC motor. The switching pulse of the SEPIC and the 3-LCEDC inverter is indicated in Figure 25. The set speed response is shown in Figure 26, and the equivalent speed response for $1000 \mathrm{rpm}$ without load is shown in Figure 27, where the speed increases steadily until 0.5 seconds and then settles to $1000 \mathrm{rpm}$, and with applied load are shown in Figure 28, where speed oscillates and then settles to set the speed. During load conditions, the speed oscillates initially and then settles to the set speed. The experimental speed and simulation speed waveform of BLDC motor in Figure 27 and Figure 13 closely matches and hence it is experimentally validated.

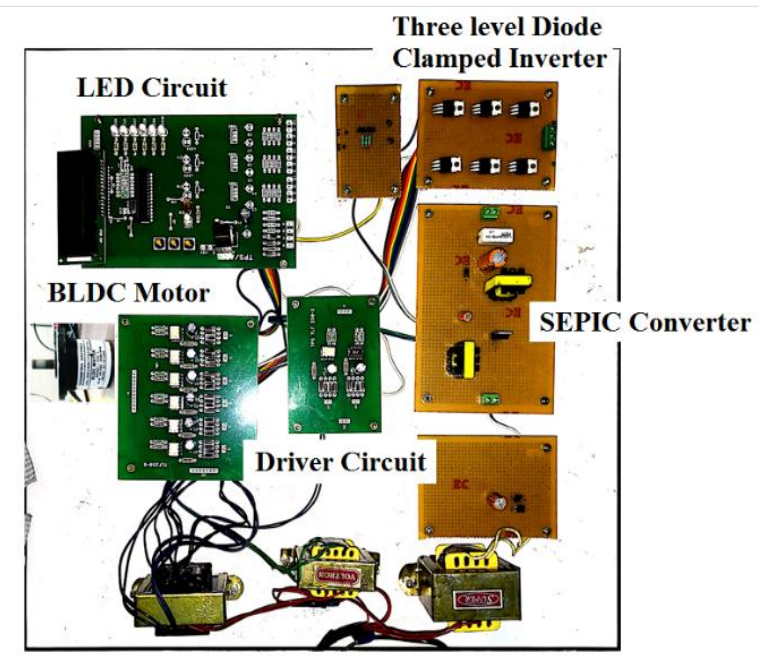

Figure 24 Experimental setup of BLDC drive system

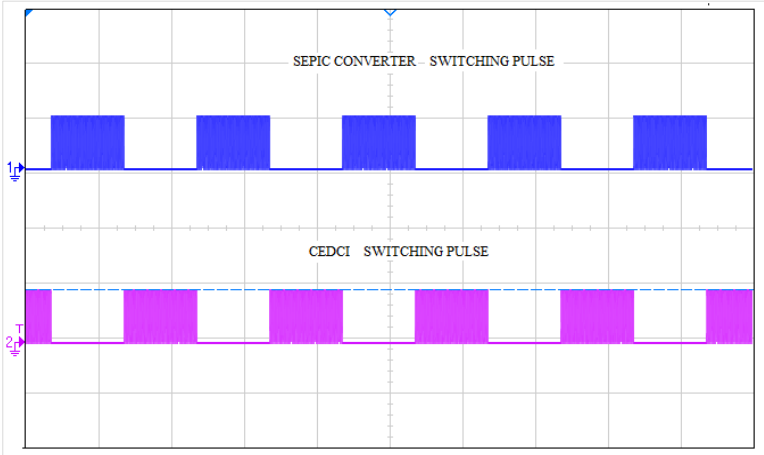

Figure 25 Switching pulse of SEPIC and 3-LCEDC inverter 1652

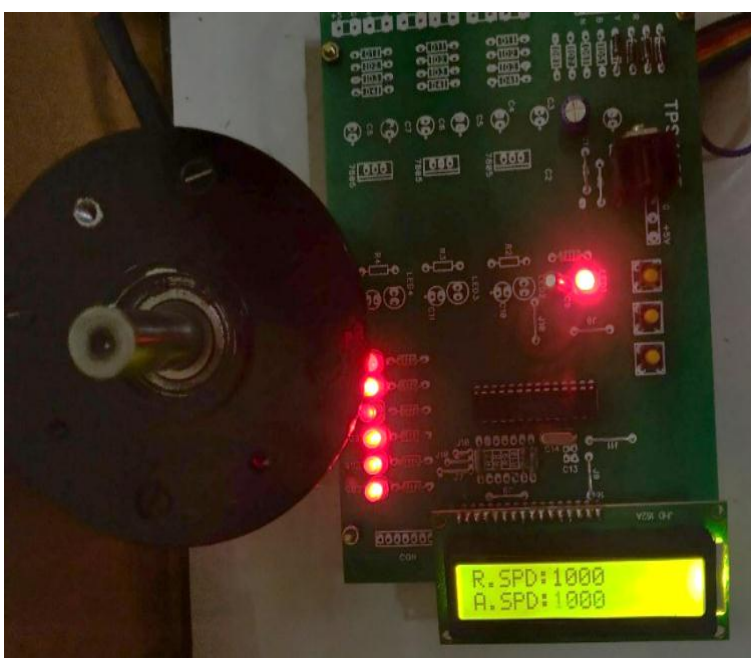

Figure 26 Speed output without load

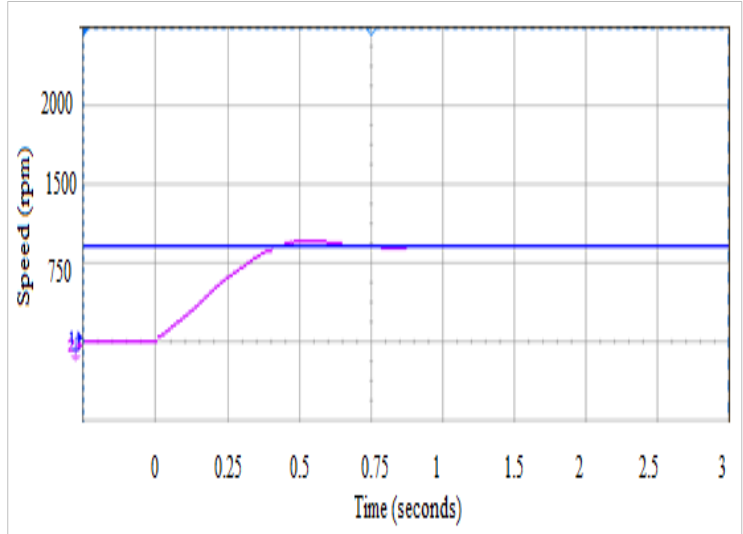

Figure 27 Experimental BLDC motor speed waveform

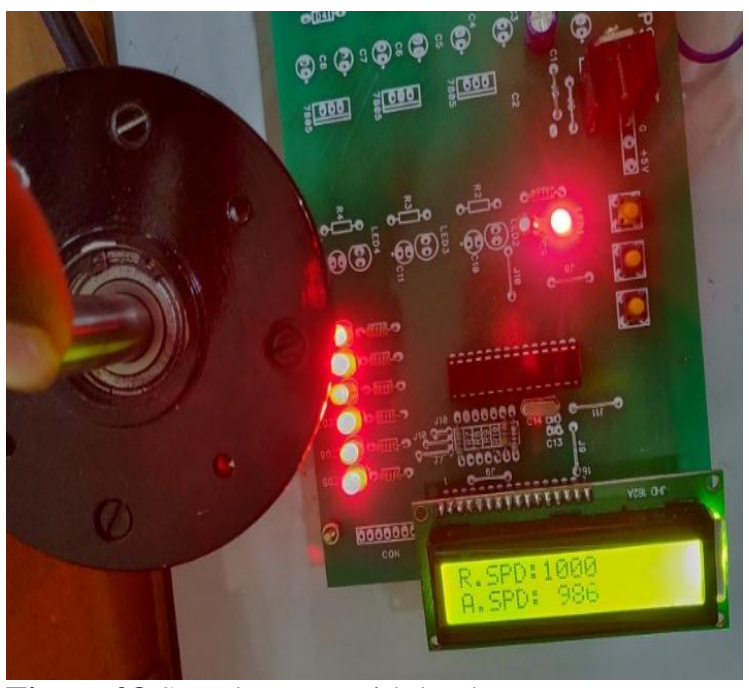

Figure 28 Speed output with load 


\section{Discussion}

The simulation of a 3-LCEDCI with SEPI converter for $5 \mathrm{kHz}$ switching frequency trapezoidal BLDC motor with a torque constant of $60.70 \mathrm{Nm} / \mathrm{A}$ peak is simulated using MATLAB/Simulink. Modified SEPIC provides positive constant supply voltage with additional diodes and filters. Diode clamped inverter clamps, various steps in the output voltage. Common point added in diode clamp inverter to provide circulating current and additionally four switches added in the DC side to avoid commutation overlap. Switching pulse for four switches is obtained from stator back emf of BLDC motor using logic gates. The performance parameters of modified SEPIC and the 3-LCEDC inverter fed BLDC motor is depicted for voltage, current, speed, and torque with PI controller. SEPI converter current waveform and 3LCEDC inverter output voltage, phase A voltage, current and back emf of BLDC motor are shown in Figure 9 to 14. The speed response of BLDC motor under no-load and load waveforms is shown where the speed remains constant irrespective of load torque variations and the corresponding electromagnetic torque is shown in Figure 16 for static and dynamic load variations. Torque ripple during equilibrium condition after reaching the steady-state is shown in Figure 17. Further to improve the dynamic performance, fuzzy controller added along with a PI controller to reduce the overshot response of speed when load torque is applied and also to reduce the torque ripple. Load torques are applied gradually and the corresponding speed response is shown where the speed overshoots for a fraction of a period and settles to set the speed. The speed remains constant irrespective of load torque variations and the corresponding torque ripple is very less with the PI controller as shown in Figure 23.

The simulation study is validated using an experimental setup for the switching frequency of 5 $\mathrm{kHz}$. The experimental speed response matches with the simulation results where the set speed of 1000 rpm closely matches with the actual speed of the motor. The improved 3-LCEDC inverter with SEPIC reduces the ripple and maintains constant voltage irrespective of the number of switches compared with the three-level common end diode clamped inverter. The limitation of the proposed method will produce more torque undulation for high switching frequency but reduce the commutation overlap. The torque undulation for $5 \mathrm{kHz}$ switching frequency for a speed of $1000 \mathrm{rpm}$ with PI controller is $12.72 \%$ and with the fuzzy controller, the undulation is $11 \%$. Table 4 and Table 5 compare the torque and current undulation with and without fuzzy controllers for various switching frequencies and different set speeds. The torque undulation in percentage is very less for high speed. A complete list of abbreviations is shown in Appendix I.

\section{Conclusion and future work}

This paper proposes torque distortion improvement in BLDC motor using SEPIC and a 3-LCEDC inverter. Simulation is carried out for a wide range of speeds under various switching frequencies and the torque undulation is calculated in percentage. The torque undulation is very less for fuzzy-based BLDC motors. The experimental validation for speed waveform is compared with simulation results for a switching frequency of $5 \mathrm{kHz}$. Thus the proposed improved SEPIC with 3-LCEDCI reduces the current and torque undulation. In the future, additional methods can be implemented to decrease the torque undulation for high switching frequency further.

Future work is as follows.

- Reduce the number of switches in the DC-DC converter.

- The 3-LCEDC inverter can be increased to higher levels to obtain smooth output voltage and also to reduce undulation at high frequency.

- FLC system can be replaced by a Genetic Algorithm, Neuro-Fuzzy, or any Artificial Intelligence System (AIS) to improve the smooth response.

\section{Acknowledgment}

The authors would like to thank the Panimalar Engineering College, Chennai for continuous support and encouragement to carry out the research.

\section{Conflicts of interest}

The authors have no conflicts of interest to declare.

\section{References}

[1] Gamazo-real JC, Vázquez-sánchez E, Gómez-gil J. Position and speed control of brushless DC motors using sensorless techniques and application trends. Sensors. 2010; 10(7):6901-47.

[2] Huang X, Goodman A, Gerada C, Fang Y, Lu Q. A single sided matrix converter drive for a brushless DC motor in aerospace applications. IEEE Transactions on Industrial Electronics. 2011; 59(9):3542-52.

[3] Huang X, Goodman A, Gerada C, Fang Y, Lu Q. Design of a five-phase brushless DC motor for a safety critical aerospace application. IEEE Transactions on Industrial Electronics. 2011; 59(9):3532-41.

[4] Sheng T, Wang X, Zhang J, Deng Z. Torque-ripple mitigation for brushless DC machine drive system using one-cycle average torque control. IEEE 
Transactions on Industrial Electronics. 2014; 62(4):2114-22.

[5] Viswanathan V, Jeevananthan S. Approach for torque ripple reduction for brushless DC motor based on three-level neutral-point-clamped inverter with DCDC converter. IET Power Electronics. 2015; 8(1):4755.

[6] Xia C, Xiao Y, Chen W, Shi T. Torque ripple reduction in brushless DC drives based on reference current optimization using integral variable structure control. IEEE Transactions on Industrial Electronics. 2013; 61(2):738-52.

[7] Anvari B, Shirinabadi M, Afjei E. Design and simulation of Z-source inverter for brushless DC motor drive. International Research Journal of Applied and Basic Sciences. 2013; 7:417-21.

[8] Arunkumar S, Thangavel S. A review paper on torque ripple reduction in brushless DC motor drives with different multilevel inverter topology. TELKOMNIKA Indonesian Journal of Electrical Engineering. 2015; 13(1):65-75.

[9] Ozturk SB, Toliyat HA. Direct torque and indirect flux control of brushless DC motor. IEEE/ASME Transactions on Mechatronics. 2010; 16(2):351-60.

[10] Buja G, Bertoluzzo M, Keshri RK. Torque ripple-free operation of PM BLDC drives with petal-wave current supply. IEEE Transactions on Industrial Electronics. 2014; 62(7):4034-43.

[11] Fang J, Zhou X, Liu G. Instantaneous torque control of small inductance brushless DC motor. IEEE Transactions on Power Electronics. 2012; 27(12):4952-64.

[12] Fang J, Zhou X, Liu G. Precise accelerated torque control for small inductance brushless DC motor. IEEE Transactions on Power Electronics. 2012; 28(3):1400-12.

[13] Goswami R, Joshi D. Performance review of fuzzy logic based controllers employed in brushless DC motor. Procedia Computer Science. 2018; 132:623-31.

[14] Navaneethakkannan C, Sudha M. Analysis and implementation of ANFIS-based rotor position controller for BLDC motors. Journal of Power Electronics. 2016; 16(2):564-71.

[15] Gowthamraj T, Kumar BR. Design of SEPIC converter for BLDC motor from photovoltaic cell. In international conference on electrical, instrumentation and communication engineering 2017.

[16] Viswanathan V, Seenithangom J. Commutation torque ripple reduction in the BLDC motor using modified SEPIC and three-level NPC inverter. IEEE Transactions on Power Electronics. 2017; 33(1):53546.

[17] Prathibanandhi K, Ramesh R. Hybrid control technique for minimizing the torque ripple of brushless direct current motor. Measurement and Control. 2018; 51(7-8):321-35

[18] Kumar SD, Chockalingam A. Design of sepic convetrer controlled BLDC motor for electric vehicle. International Journal of Recent Technology and Engineering (IJRTE). 2009; 8(4): 8994-7.
[19] Diofode R, Suryawanshi J. Control of BLDC motor using PV fed bridgeless single switch SEPIC converter. International Journal of Innovative Technology and Exploring Engineering. 2019; 9(1):2575-80.

[20] Deshpande P, Mopari SS, Swami PS. Power factor correction and power quality improvement in BLDC motor drive using SEPIC converter. In international conference on electrical, computer and communication technologies 2019 (pp. 1-4). IEEE.

[21] Ramkumar R, Ezhilarasi M, Sonar D. PV based SEPIC converter fed four switch BLDC motor drive. Advances in Natural and Applied Sciences. 2016; 10(3):129-36.

[22] Vinatha U. FPGA based experimental evaluation of BLDC motor drive fed from coupled inductor based bridgeless SEPIC. In international conference on power electronics, smart grid and renewable energy 2020 (pp. 1-6). IEEE.

[23] Senthilnathan A, Palanivel P. A new approach for commutation torque ripple reduction of FPGA based brushless DC motor with outgoing phase current control. Microprocessors and Microsystems. 2020.

[24] Kavin KS, Subha KP. PV-based grid interactive PMBLDC electric vehicle with high gain interleaved DC-DC SEPIC converter. IETE Journal of Research. 2021:1-5.

[25] Yao X, Zhao J, Wang J, Huang S, Jiang Y. Commutation torque ripple reduction for brushless DC motor based on an auxiliary step-up circuit. IEEE Access. 2019; 7:138721-31.

[26] Cao Y, Shi T, Li X, Chen W, Xia C. A commutation torque ripple suppression strategy for brushless DC motor based on diode-assisted buck-boost inverter. IEEE Transactions on Power Electronics. 2018; 34(6):5594-605.

[27] Knypiński Ł， Kuroczycki S， Márquez FP. Minimization of torque ripple in the brushless DC motor using constrained cuckoo search algorithm. Electronics. 2021; 10(18):1-20.

[28] Huang Q, Luo L, Zhang Y, Cao J. Commutation torque ripple suppression in three phase brushless DC motor using open-end winding. International Journal of Control, Automation and Systems. 2021; 19:274758.

[29] Nadesan MK, Kaliappan E, Chellamuthu C. Analysis and simulation of cascaded five and seven level multilevel inverter fed induction motor. Journal of Theoretical and Applied Information Technology. 2014; 63(3):615-25.

[30] Nadesan MK, Chellamuthu C, Prabhakaran KK. Simulation and implementation of diode clamped multilevel inverter fed induction motor. International Journal of Applied Engineering Research. 2014; 9(21):11433-52.

[31] Nadesan MK, Ramadas G, Chinnagounder C. A novel multilevel inverter circuit for the performance enhancement of direct torque controlled induction motor. Circuits and Systems. 2016; 7(9):2771-94. 
[32] Nadesan MK, Sanjay L, Hariharan H, Manikandan MV, Kumar EM. Diode clamped multilevel inverter fed BLDC motor using SEPIC converter. International conference for phoenixes on emerging current trends in engineering and management 2019 (pp.1-5).

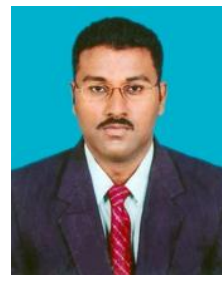

Dr. Manoj Kumar $\mathbf{N}$ was born in April 1983. He received his bachelor's degree in Electrical and Electronics Engineering from Madras University, Chennai. He received his Master's Degree from Sathyabama Institute of Science and Technology and a Ph.D. degree from Anna University. At present, he is working as Associate Professor at Panimalar Engineering College, Chennai, Tamilnadu. His areas of interest are Power Electronics, Drives, and Renewable Energy.

Email: manojkumarnsvcet@gmail.com

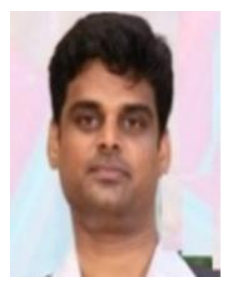

Dr. Kavaskar $\mathbf{S}$ received his bachelor's degree in Electrical and Electronics Engineering from Madras University, Chennai. He received his Master's degree from Anna University and Ph.D. degree under Anna University. His area of interest includes Power Systems, Smart Grid, Renewable Energy and

Deep Learning.

Email: kavaskarsekar@gmail.com

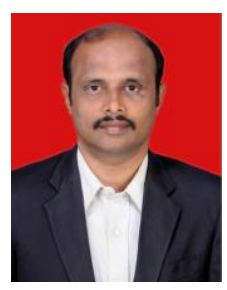

Dr. Hariramakrishnan $\mathbf{P}$ received his bachelor's degree in Electrical and Electronics Engineering from Madras University, Chennai. He received his Master's degree from Anna University and Ph.D. degree under Sathyabama Institute of Science and Technology. At present, he is working as Associate Professor at Panimalar Engineering College, Chennai, and Tamilnadu. His areas of interest are the Power Quality in Power Systems, Machine Learning, and Deep Learning Techniques.

Email: harirmk@gmail.com
Appendix-I

\begin{tabular}{|c|c|c|}
\hline S. No. & Abbreviation & Description \\
\hline 1 & ANFIS & $\begin{array}{l}\text { Adaptive Neuro-Fuzzy } \text { Interference } \\
\text { System }\end{array}$ \\
\hline 2 & BLDC & Brushless Direct Current \\
\hline 3 & CECI & Common End Diode Clamped Inverter \\
\hline 4 & $\mathrm{CCM}$ & Continuous Conduction Mode \\
\hline 5 & DTC & Direct Torque Control \\
\hline 6 & emf & Electromotive Force \\
\hline 7 & FPGA & Field Programmable Gate Array \\
\hline 8 & FOPID & $\begin{array}{l}\text { Fraction Order Proportional Integral } \\
\text { Derivative }\end{array}$ \\
\hline 9 & FR & Fuzzy Regulator \\
\hline 10 & FLC & Fuzzy Logic Control \\
\hline 11 & IM & Induction Motor \\
\hline 12 & LCD & Liquid Crystal Display \\
\hline 13 & MPPT & Maximum Power Point Tracking \\
\hline 14 & OCDHC & $\begin{array}{l}\text { Outgoing-Phase Current Discharge } \\
\text { Hysteresis Control }\end{array}$ \\
\hline 15 & PI & Proportional Integral \\
\hline 16 & PID & Proportional Integral Derivative \\
\hline 17 & PMSMS & $\begin{array}{l}\text { Permanent Magnet } \\
\text { Motor }\end{array}$ \\
\hline 18 & PV & Photovoltaic \\
\hline 19 & $\mathrm{RC}$ & Resistor Capacitor \\
\hline 20 & RL & Resistor Inductor \\
\hline 21 & SEPIC & $\begin{array}{lll}\text { Single-Ended } & \text { Primary } & \text { Inductor } \\
\text { Converter } & & \\
\end{array}$ \\
\hline 22 & SCE & Sinusoidal Counter-Electromotive \\
\hline 23 & SCF & Sinusoidal Counter Emf \\
\hline 24 & TCE & $\begin{array}{l}\text { Trapezoidal Counter-Electromotive } \\
\text { Force }\end{array}$ \\
\hline 25 & TCF & Trapezoidal Counter Emf \\
\hline 26 & THD & Total Harmonic Distortion \\
\hline 27 & VSI & Voltage Source Inverter \\
\hline 28 & 3-LCEDCI & $\begin{array}{l}\text { 3-Level Common End Diode Clamped } \\
\text { Inverter }\end{array}$ \\
\hline
\end{tabular}

